\title{
Sobre el ente nacional superior del cooperativismo y de la economía social y solidaria en Iberoamérica
}

(On the higher national entity of cooperativism and social and solidary economy in Latin America)

\author{
Alberto García Müller ${ }^{1}$ \\ Universidad de los Andes
}

Reclbído: 25.05.2014

Aceptado: 30.07.2014

Sumario: I. Concepto. 1.1. Acepciones. 1.2. Antecedentes. 1.3. Sistema. II. Régimen jurídico. 2.1. Naturaleza. 2.2. Objetivos. 2.3. Miembros. 2.4. Financiamiento. 2.5. Estructura organizativa. III. Atribuciones y funciones. 3.1. Consultivas. 3.2. Atribuciones propias. IV. Conclusiones. V. Bibliografía.

Resumen: El presente trabajo tiene por objetivo analizar el marco regulatorio del ente que articula, coordina y, o representa al conjunto de organizaciones cooperativas de un país y, por extensión, al sector de economía social y solidaria. Comprende el estudio de su concepto, antecedentes, sistema, naturaleza, objetivos, miembros, financiamiento, estructura organizativa, sus atribuciones y funciones, así como una relación sucinta de los entes nacionales superiores en Iberoamérica.

Palabras clave: ente, nacional, superior, cooperativas, economía social, solidaria

Abstract: This paper aims to analyse the regulatory framework of the entity which articulates, coordinates and/or represents all the cooperative organisations of a country and, by extension, the social and solidarity economy sector. It includes the study of its concept, background, system, nature, objectives, members, funding, organisational structure, powers and functions, as well as a brief account of the higher national entities in Latin America.

Key words: entity, national, higher, cooperatives, social economy, solidarity.

1 Correo electrónico: agamuller@gmail.com 


\section{Concepto}

\section{II.1. Acepciones}

El organismo nacional superior puede ser entendido:

a) En su acepción reducida, como el organismo nacional de integración de cada una de las manifestaciones solidarias existentes en un país, bien sea de las cooperativas, de las mutuales y de otras empresas asociativas, cada una por separado, por ejemplo, una confederación nacional de cooperativas que reúne a todas las cooperativas del país, cualquiera sea su tipo o clase, a la par de una confederación de mutuales, por ejemplo.

b) En su acepción amplia, es el organismo nacional del sector social o solidario en su conjunto donde participan todos los subsectores que lo componen. En este último sentido, es el organismo que formula y coordina, a nivel nacional, las políticas, estrategias, planes, programas y proyectos generales pertinentes al sistema de la economía solidaria tal y como lo hace la Ley 454 de Colombia, de 1998.

\subsection{Antecedentes}

El más antiguo antecedente es el Consejo Superior de Cooperativas de Francia creado por Decreto del 22 de febrero de 1918 que inspira los consejos cooperativos de España. Nace adherido y condicionado a la voluntad gubernativa, dependiente del Ministerio del Trabajo, siendo un punto de conexión y colaboración entre las cooperativas y el Gobierno.

En España surge en Cataluña con la ley de cooperativas de 1942 y se encuentra en casi todas las leyes autonómicas de cooperativas, siendo el más destacado el Consejo Superior de Cooperativas de Euskadi que desde el comienzo de sus actividades en 1983 ha cumplido una labor de significativa importancia contribuyendo enormemente al impulso del cooperativismo vasco, siendo una fórmula en la que se conjugan tanto el interés del Estado como también el de los cooperativistas (Buitrón, 1998).

\section{I.3. Sistema}

a) Puede tratarse de entidad única nacional vértice como es el caso de la mayoría de las leyes de América Latina (diez y siete leyes de veintiséis), articuladora del sector solidario exclusiva- 
mente (veinte leyes) o ampliada, como punto de conexión entre el gobierno y el sector (seis leyes) que constituye un órgano público integrado por representantes de las administraciones públicas y de las cooperativas o las entidades sociales o solidarias.

- La OIT (2000) observa que si se prescribe la existencia de una sola organización coordinadora de las cooperativas y su objeto se formula en la legislación cooperativa, hay el peligro de que esta coordinadora se convierta en un mecanismo burocrático en lugar de ser una organización dinámica de fomento, propagando nuevas ideas y tecnologías entre las organizaciones asociadas y representando los intereses del movimiento cooperativo ante el gobierno y el público en general.

— Este peligro es todavía mayor — añade- cuando las organizaciones nacionales coordinadoras legalmente prescritas no son financiadas por sus afiliados, sino que dependen de las subvenciones del gobierno o de los donantes extranjeros. Donde existen varias organizaciones no excluye las actividades conjuntas como la representación de intereses ante el gobierno en cuestiones que afecten a todas las cooperativas. Esto puede hacerse formando un comité ad-hoc, una comisión permanente con presidencia rotatoria bianual.

b) Pareciera lo más conveniente la creación de un organismo nacional y consejos regionales, provinciales o estatales e, incluso, locales, con las mismas funciones, atribuciones y responsabilidades de aquel, en el ámbito geográfico determinado, pero integrado por organismos de segundo grado que operen exclusivamente dentro de la jurisdicción territorial.

- Sin embargo, el problema que se presenta cuando existe más de una confederación es que el Estado puede cuestionar cuál sea la interlocutora válida y esto genera una debilidad, ya sea del movimiento cooperativo o del mutual, que aprovechará el propio Estado para no acordar políticas con el sector o dictarlas solo a su antojo.

\section{Régimen jurídico}

\section{II.1. Naturaleza}

La doctrina se viene decantando porque se trate de una entidad pública no estatal que ejerza funciones públicas, aunque no forme 
parte de la estructura burocrática del gobierno ni tenga dependencia jerárquica del mismo, y esté dotado de autonomía en el ejercicio de sus funciones propias. Tal es el caso del Consejo para el fomento de la economía social de España, que es un órgano público (pero no sometido al principio de jerarquía administrativa) colegiado, de carácter asesor y consultivo y cuya composición grupal es trimembre: Administraciones Públicas, Asociaciones de diverso carácter (de base pública local, de la economía social — confederal e infra confederal-y sindical) y, finalmente, los expertos. Es un órgano de consulta y asesoramiento que no comporta la misión fomentadora (Paz, 2012).

Con frecuencia también suele ser una entidad de naturaleza privada, o puede ser una institución exclusivamente de naturaleza cooperativa, mutual o solidaria; o reunir entidades de diferentes clases de la economía social.

No es muy frecuente (seis de veintiséis leyes) la participación del Estado en la organización y funcionamiento del organismo nacional superior a través de representantes normalmente de los ministerios encargados de la economía, la agricultura, el comercio y la industria. Esa participación puede darse en forma paritaria con los representantes del sector, mayoritaria o minoritaria.

Por lo general, la entidad goza de personería jurídica y de patrimonio propio, aunque en ciertos casos se trata de instancias administrativas menores. Es posible que goce de autonomía plena, aunque es frecuente que sea dotada de autonomía funcional pero no administrativa, y puede estar adscrita a otra entidad pública como un Ministerio (muy raro) o ser una dependencia de menor nivel. Es normal que se disponga que no tiene fines lucrativos.

\section{II.2. Objetivos}

Aunque puedan estar indeterminados y se remita su fijación a sus normas internas o a las reglamentarias, lo normal es que sean determinados en la normativa regulatoria, a saber:

a) Definir las políticas y estrategias del sector solidario a nivel nacional; fomentar y proteger su desarrollo, y representar y defender sus derechos e intereses.

b) Registrar los organismos solidarios que componen el sector y los actos que realizan y ejercer su suprema fiscalización y control.

c) Además, servir de punto de articulación de todo el sector y punto de conexión y colaboración entre el Gobierno y el Sector. 
En España es el ente nacional solidario es el reflejo institucionalizado del federacionismo cooperativo; máximo órgano de promoción y representación de cooperativas. Tiene personería jurídica propia y plena capacidad de obrar, constituyéndose en un órgano jurídico público, integrado mayoritariamente, en todo caso, por representantes de las cooperativas; y cuyo principio informador supremo es el fomento y estudio cooperativista. Ejerce funciones de trascendencia jurídico-pública, puesto que vincula a los poderes públicos, defendiendo ante ellos los intereses privados que representan.

Desarrolla actividades de dirección puramente interna. Es un órgano puramente de ínter colaboración entre el movimiento y las uniones; orienta la propaganda de la cooperación; acuerda el destino que debe darse a los fondos de obras sociales de las cooperativas que se disuelvan cuando estas no lo hubieran hecho; interviene en la redacción de los reglamentos tipo de las cooperativas (Arrieta, 1998).

\section{II.3. Miembros}

El organismo nacional superior puede estar conformado exclusivamente por miembros procedentes del sector cuyo número esté determinado en su instrumento de creación o ello se deja a normas de carácter reglamentario. Normalmente, está compuesto por representantes de las todas las cooperativas, o de los diversos sectores de estas, por ejemplo, de las agrarias, de vivienda. Pero nada obsta a que tengan representantes de las mutuales, de las cajas de ahorro y de crédito, sociales de compensación; de las empresas comunales, solidarias, de los trabajadores; de los ejidos y demás entidades afines.

Representantes de otros sectores sociales .A veces se da participación a representantes del sector obrero, campesino, comercial, vecinal, etc. Lo mismo que se establecen porcentajes de participación de cada uno de los sectores bien sea en forma paritaria o mayoritaria.

Es poco frecuente la participación de representantes del Estado en el mismo.

\section{II.4. Financiamiento}

a) Puede provenir del propio sector con fondos aportados por las entidades que lo integran, según determinado porcentaje de sus recursos económicos o del número de miembros de base, bien sea por una cantidad fija, además de lo recaudado por las 
multas que en algunos casos se les autoriza a imponer a las entidades que incurran en faltas o irregularidades en su funcionamiento.

- En Galicia, el Consejo Superior se financia con las partidas asignadas por el presupuesto de la Comunidad Autónoma; las sumas aportadas por las cooperativas con parte del fondo de educación; con la totalidad del fondo de reserva obligatorio de las cooperativas y los remanentes de las liquidadas (Comesaña, 2001).

- La ley de Brasil (1971) establece con carácter obligatorio una «contribución cooperativista» para financiar la Organización de Cooperativas Brasileñas, igual al $0.2 \%$ del valor del capital integrado y los fondos de las cooperativas en el ejercicio social del año anterior. Périus (2001) considera que su naturaleza jurídica se asemeja más a una «obligación de contribuir», modalidad de la obligación de dar, rigiéndose de esta forma por las normas referentes a las obligaciones pecuniarias.

b) El organismo nacional superior podría desarrollar actividades económicas para su sostenimiento, preferentemente por medio de empresas solidarias operadoras o por empresas de otra forma jurídica, siempre que no le hicieren competencia desleal o ruinosa a otras empresas solidarias $u$ organismos de integración.

c) Podrían recibir aportes del Estado, paritarios o proporcionales a los aportes de las entidades que lo componen. Pudiese ser que actúen como operadores de financiamiento estatal al sector, cubriendo parte de sus gastos con las comisiones que les correspondan por el ejercicio de la actividad crediticia. Incluso, podría financiarse con algún impuesto o tasa especial creada para su mantenimiento.

\section{II.5. Estructura organizativa}

Generalmente tiene una estructura organizativa compleja, compuesta de múltiples órganos internos, entre los cuales se destacan:

a) Órgano deliberante

La entidad cúpula nacional generalmente cuenta con un órgano superior colectivo, integrado con representantes de los diversos subsectores (cooperativas, mutuales y otras empresas); de los 
sectores campesino, obrero o comercial; y del Estado, que cumplan los requisitos determinados en la ley o remitidos a las normas internas. Su designación puede ser hecha directamente por el sector o por el estado, de manera libre o a propuesta del propio sector. Ejerce funciones de aprobación de las políticas, estrategias y planes de las atribuciones asignadas al consejo, así como las funciones genéricas necesarias al cumplimiento de su objeto. Todo lo relacionado con la periodicidad de sus sesiones, quórum, mayorías, presidencia y demás detalles de funcionamiento normalmente es objeto de remisión a las normas internas que se le faculta para dictar.

b) Órganos directivo

Preferentemente de carácter colectivo, es designado por el órgano deliberante, aunque en ciertos casos - por ley- lo preside el titular de la Autoridad de aplicación. Su composición (individual o colegiada) número de integrantes, sesiones, etc., es objeto de remisión a las normas internas. Tiene por principales funciones la ejecución de las decisiones del órgano deliberante, la coordinación de las actividades del organismo, y todas las necesarias para el cumplimiento de su objeto.

c) Otros órganos internos

Ejecutivo y de control. En Italia, un Comité integrado por algunos miembros que ejerce las funciones del organismo en caso de urgencia.

\section{Atribuciones y funciones}

El ente nacional superior puede tener atribuciones meramente consultivas o propias, esto es, de diferente alcance y contenido que veremos a continuación. Una mayoría determinante de las leyes analizadas (veintidós de veintiséis) confieren al ente nacional superior potestades propias, y sólo dos, de mero carácter consultivo.

\section{III.1. Consultivas}

Servir de órgano consejero (de consulta de carácter obligatorio o potestativo) con efecto generalmente recomendatorio (que no vinculante) de los poderes públicos nacionales en asuntos relacionados con el cooperativismo, el mutualismo o la economía social solidaria, así como para la elaboración de proyectos de ley sobre la materia. 
Puede ser, también, de ejercer la representación internacional de la economía solidaria nacional.

\section{III.2. Atribuciones propias}

a) Definición de políticas y estrategias

- Propender a la máxima articulación de la economía solidaria, fomentar la difusión de los principios y valores solidarios, asumir las actividades de educación, capacitación y entrenamiento de los cuadros de dirección del sector, dirigir la elaboración y el cumplimiento del plan nacional de desarrollo de la economía solidaria y defender los derechos y preferencias acordados a esta.

- Definir las políticas y estrategias de la economía solidaria a nivel nacional en materia educativa, financiera, administrativa, social, tecnológica y las demás necesarias para su desarrollo y consolidación

b) De representación

- Representa al sector social y solidario ante los entes públicos nacionales y relacionados, la Autoridad de aplicación o de fomento y ante las autoridades administrativas, judiciales, y gremiales, asumiendo funciones de conexión entre el sector y los organismos del Estado en sus expresiones nacional, regional y local.

- Ejerce la representación y defensa judicial y administrativa, de pleno derecho o por mandato legal expreso del sector, tanto nacional como internacional, así como la defensa de los derechos y preferencias reconocidas al sector.

c) Aspectos normativos o legislativos

- Potestad de dictado de actos normativos generales de rango sub-legal; emisión de las normas especiales aplicables a los tipos y clases de empresas solidarias que se constituyan, aprobación de los modelos supletorios de normas internas, de las normas para la emisión de títulos externos, para la actualización del patrimonio, para el uso de sistemas computarizados de contabilidad, sobre el balance social y las demás que fueren necesarias o convenientes al desarrollo de la economía solidaria en el país. 
- Dictar sus propias normas de funcionamiento y las del mecanismo nacional de conciliación y arbitraje; las normas de funcionamiento del sistema nacional de financiamiento del sector; del sistema nacional de garantías para las empresas del sector; de la Autoridad de aplicación, si fuere el caso;

- De coordinación de actividades entre la Autoridad de aplicación y los organismos estadales y provinciales de control de la economía solidaria y del registro del sector.

- Dictar por sí mismo o junto con los organismos públicos competentes las normas especiales para las empresas solidarias que lo requieran por su naturaleza o por el tipo de actividades que desarrollen, y dictar los demás actos normativos que fueren necesarios.

- Elaborar proyectos normativos de carácter legislativo o reglamentario; dictar pautas, directrices y normas operativas obligatorias para las empresas solidarias y los organismos de integración en materia administrativa, contable y financiera;

- Establecer y reglamentar los sistemas y procedimientos generales de control, el sistema nacional de auditoría, los planes contables uniformes o por sub-sectores y las demás que fueren necesarios.

d) Fomento y desarrollo del sector

- Desarrollar proyectos de producción, transformación, distribución, aprovisionamiento y consumo solidario.

- Servir de brazo financiero para el desarrollo del sector, por medio de un fondo de financiamiento (más uno de garantías) adecuados a las características propias de las entidades solidarias, con fondos provenientes de las y aportes del Estado proporcionales a los aportados por el sector.

- Impulsar proyectos nacionales, binacionales e internacionales de producción, prestación u obtención de bienes y servicios de economía solidaria, por medio de empresas solidarias, organismos de integración o de acuerdos de agrupación o colaboración empresarial.

e) Fiscalización y control sectorial

- Definición de medidas y de procedimientos de control de operaciones de las empresas solidarias, así como establecer sistemas nacionales o regionales de auditora. En Bélgica, el Consejo Nacional del Cooperativismo es el organismo responsable de gestionar y supervisar el registro de las coo- 
perativas homologadas y de velar por la correcta aplicación de sus correspondientes estatutos (Moyano, 1993).

— Imposición de sanciones por irregularidades

- Conocimiento por vía jerárquica de los recursos administrativos contra los actos y decisiones de la Autoridad nacional de aplicación, del sistema nacional de financiamiento del sector solidario y de los mecanismos de registro del sector.

- Solicitar al juez competente la intervención y liquidación de las empresas solidarias.

- Denunciar ante las autoridades judiciales y administrativas los delitos y faltas cometidas contra las empresas solidarias y los organismos de integración, así como constituir instancia suprema de conciliación y arbitraje de la economía solidaria a nivel nacional.

\section{f) Otros}

Realizar todos los actos, contratos, actividades y operaciones que fueren necesarias o convenientes para el cumplimiento de sus atribuciones y funciones.

\section{Cuadro 1. Entes nacionales superiores en Iberoamérica}

\begin{tabular}{|c|c|c|c|c|c|c|c|}
\hline \multirow[b]{2}{*}{ Cooperativas } & \multirow[t]{2}{*}{ Denominación } & \multicolumn{2}{|c|}{ Carácter } & \multicolumn{2}{|c|}{ Funciones } & \multicolumn{2}{|c|}{ Composición } \\
\hline & & Único & $\begin{array}{l}\text { Múlti- } \\
\text { ple }\end{array}$ & $\begin{array}{l}\text { Consul- } \\
\text { tor }\end{array}$ & Propias & Sector & $\begin{array}{l}\text { Estado- } \\
\text { Sector }\end{array}$ \\
\hline $\begin{array}{l}\text { Colombia } \\
1988\end{array}$ & $\begin{array}{l}\text { Consejo Nacional } \\
\text { Cooperativo }\end{array}$ & $x$ & & $x$ & & & $x$ \\
\hline $\begin{array}{l}\text { Bolivia } \\
2013\end{array}$ & $\begin{array}{l}\text { Confederación Nacio- } \\
\text { nal de Cooperativas } \\
\text { de Bolivia }\end{array}$ & $x$ & & & $x$ & $x$ & \\
\hline $\begin{array}{l}\text { Brasil } \\
1971\end{array}$ & $\begin{array}{l}\text { Conselho Nacional de } \\
\text { Cooperativismo }\end{array}$ & $x$ & & & $x$ & & $x$ \\
\hline $\begin{array}{l}\text { Chile } \\
2004\end{array}$ & Confederaciones & & $x$ & & $x$ & $x$ & \\
\hline $\begin{array}{l}\text { Costa Rica } \\
1982\end{array}$ & $\begin{array}{l}\text { Consejo Nacional } \\
\text { Cooperativo }\end{array}$ & & $x$ & & $x$ & $x$ & \\
\hline $\begin{array}{l}\text { El Salvador } \\
1979\end{array}$ & $\begin{array}{l}\text { Confederación Nacio- } \\
\text { nal de Cooperativas } \\
\text { del El Salvador }\end{array}$ & $x$ & & & $x$ & $x$ & \\
\hline $\begin{array}{l}\text { Guatemala } \\
1978\end{array}$ & Confederación & $x$ & & & $x$ & $x$ & \\
\hline $\begin{array}{l}\text { Honduras } \\
1987\end{array}$ & $\begin{array}{l}\text { Confederación Hondu- } \\
\text { reña de Cooperativas }\end{array}$ & & $x$ & & $x$ & $x$ & \\
\hline $\begin{array}{l}\text { México } \\
2001\end{array}$ & $\begin{array}{l}\text { Consejo Superior del } \\
\text { Cooperativismo }\end{array}$ & $x$ & & & $x$ & $x$ & \\
\hline $\begin{array}{l}\text { Nicaragua } \\
2004\end{array}$ & $\begin{array}{l}\text { Consejo Nacional de } \\
\text { Cooperativas }\end{array}$ & $x$ & & & $x$ & $x$ & \\
\hline
\end{tabular}




\begin{tabular}{|c|c|c|c|c|c|c|c|}
\hline \multirow[b]{2}{*}{ Cooperativas } & \multirow[t]{2}{*}{ Denominación } & \multicolumn{2}{|c|}{ Carácter } & \multicolumn{2}{|c|}{ Funciones } & \multicolumn{2}{|c|}{ Composición } \\
\hline & & Único & $\begin{array}{l}\text { Múlti- } \\
\text { ple }\end{array}$ & $\begin{array}{l}\text { Consul- } \\
\text { tor }\end{array}$ & Propias & Sector & $\begin{array}{l}\text { Estado- } \\
\text { Sector }\end{array}$ \\
\hline $\begin{array}{l}\text { Panamá } \\
1977\end{array}$ & $\begin{array}{l}\text { Confederación Nacio- } \\
\text { nal de Cooperativas }\end{array}$ & $x$ & & & $x$ & $x$ & \\
\hline $\begin{array}{l}\text { Paraguay } \\
1994\end{array}$ & Confederación & & $x$ & & $x$ & $x$ & \\
\hline $\begin{array}{l}\text { Perú } \\
1990\end{array}$ & $\begin{array}{l}\text { Confederación de } \\
\text { Cooperativas del Perú }\end{array}$ & $x$ & & & $x$ & $x$ & \\
\hline $\begin{array}{l}\text { Puerto Rico } \\
1994\end{array}$ & $\begin{array}{l}\text { Liga de Cooperativas } \\
\text { de Puerto Rico }\end{array}$ & $x$ & & & $x$ & $x$ & \\
\hline $\begin{array}{l}\text { República } \\
\text { Dominicana } \\
1964\end{array}$ & $\begin{array}{l}\text { Confederación Nacio- } \\
\text { nal de Cooperativas }\end{array}$ & $x$ & & & $x$ & $x$ & \\
\hline $\begin{array}{l}\text { Uruguay } \\
2008\end{array}$ & $\begin{array}{l}\text { Consejo Consultivo del } \\
\text { Cooperativismo }\end{array}$ & & $x$ & & $x$ & $x$ & \\
\hline $\begin{array}{l}\text { Venezuela } \\
2001\end{array}$ & $\begin{array}{l}\text { Consejo Nacional } \\
\text { Cooperativo }\end{array}$ & $x$ & & $x$ & & & $x$ \\
\hline \multicolumn{8}{|l|}{ Mutuales } \\
\hline $\begin{array}{l}\text { Argentina } \\
2000\end{array}$ & Confederaciones & & $x$ & & $X$ & & $x$ \\
\hline $\begin{array}{l}\text { Chile } \\
1965\end{array}$ & $\begin{array}{l}\text { Confederación Mutua- } \\
\text { lista de Chile }\end{array}$ & $x$ & & & $X$ & $X$ & \\
\hline $\begin{array}{l}\text { Nicaragua } \\
2010\end{array}$ & $\begin{array}{l}\text { Confederaciones } \\
\text { mutuales }\end{array}$ & & $x$ & & $x$ & $x$ & \\
\hline $\begin{array}{l}\text { Paraguay } \\
2008\end{array}$ & $\begin{array}{l}\text { Confederaciones de } \\
\text { Mutuales }\end{array}$ & & $x$ & $x$ & & & $x$ \\
\hline \multicolumn{8}{|l|}{$\begin{array}{l}\text { Economía So- } \\
\text { cial y Solidaria }\end{array}$} \\
\hline $\begin{array}{l}\text { Honduras } \\
1985\end{array}$ & $\begin{array}{l}\text { Organismo nacional } \\
\text { de dirección y repre- } \\
\text { sentación }\end{array}$ & $x$ & & & $x$ & $x$ & \\
\hline $\begin{array}{l}\text { Colombia } \\
1998\end{array}$ & $\begin{array}{l}\text { Consejo Nacional de la } \\
\text { Economía Solidaria }\end{array}$ & $x$ & & & $x$ & $x$ & \\
\hline $\begin{array}{l}\text { Ecuador } \\
2011\end{array}$ & Confederaciones & & $x$ & & $x$ & $x$ & \\
\hline $\begin{array}{l}\text { México } \\
2011\end{array}$ & $\begin{array}{l}\text { Consejo Nacional de } \\
\text { Entidades del Sector } \\
\text { Social de la Economía }\end{array}$ & $x$ & & & $X$ & $X$ & \\
\hline $\begin{array}{l}\text { España } \\
2011\end{array}$ & $\begin{array}{l}\text { Consejo para el Fo- } \\
\text { mento de la Economía } \\
\text { Social. }\end{array}$ & $X$ & & $x$ & & & $x$ \\
\hline $\begin{array}{l}\text { Totales } \\
26\end{array}$ & & 17 & 9 & 4 & 22 & 20 & 6 \\
\hline
\end{tabular}

Fuente: elaboración propia 


\section{Conclusiones}

El régimen jurídico preferente del ente nacional superior de las cooperativas, mutuales y, o de la Economía Social y Solidaria en el área iberoamericana es el de una única entidad nacional dotada de plena autonomía que ejerce funciones de definición de sus políticas y estrategias, de representación, normativas, de fomento y desarrollo, y de fiscalización y control, conformado exclusivamente por las entidades superiores de los diversos componentes del sector.

Pareciera que la vía para que el sector social o solidario de nuestros países asegure su plena autonomía (asunción del auto-fomento y autocontrol) pasa por consolidar entidades nacionales fuertes, aunque descentralizadas, dotadas de atribuciones propias.

\section{Bibliografía}

ARRIETA, J. (1987). Política del gobierno vasco en materia cooperativa. Anuario de Estudios Cooperativos. Bilbao. Instituto de Estudios Cooperativos. Universidad de Deusto.

BUITRÓN, P. (1998). Consideraciones generales sobre el fundamento constitucional del Consejo Superior de Cooperativas de Euskadi. Boletín de la Asociación Internacional de Derecho Cooperativo. Bilbao. Universidad de Deusto.

BUITRÓN, P. (1999 y 2000). Evolución de la figura del Consejo Superior de Cooperativas en la Legislación Española. Anuario de Estudios Cooperativos 1998 y 1999. Bilbao. Instituto de Estudios Cooperativos, Universidad de Deusto.

COMESAÑA, J. (2001). Análisis de la naturaleza y el régimen jurídico de organización y funcionamiento del Consejo Gallego de Cooperativas. Revista Jurídica de la Economía Social y Cooperativa 12. Valencia. Ciriec-España.

MERINO, S. (1999). Administración Pública y Sociedades Cooperativas: el caso vasco. Estudios sobre economía social y derecho cooperativo. Madrid. Marcial Pons.

MONZÓN, J. et al (2009). Informe para la elaboración de una ley de fomento de la economía social. Valencia, Ciriec-España.

MOYANO, E. (1993). Acción colectiva y cooperativismo en la agricultura europea.Madrid, Ministerio de Agricultura, Pesca y Alimentación.

PÉRIUS, V. (2001a). Cooperativismo e Lei. Saô Leopoldo. Unisinos. 